\title{
TRABALHO INFANTIL NO BRASIL: O DILEMA ENTRE A SOBREVIVÊNCIA E A EXPLORAÇÃO
}

CHILD LABOR IN BRAZIL: THE DILEMA BETWEEN SURVIVAL AND EXPLORATION

Ana Maria Viola de Sousa

Maria Aparecida Alkimim

\section{Resumo}

O trabalho infantil é uma questão complexa que ultrapassa as noções de defesa da criança e do adolescente, imiscuindo-se nas questões socioeconômicas. Este artigo objetiva analisar os principais fatores que sustentam o trabalho infantil e suas implicações na moldagem da estrutura social na qual está inserida a família da criança trabalhadora. Na maioria das vezes, a sobrevivência da criança e da família é a causa principal do trabalho infantil, já que a subtração da renda auferida pela criança coloca a família abaixo da linha de pobreza. Nessa perspectiva, programas de combate ao trabalho infantil exigem um novo enfoque, novas estratégias de reorganização estrutural da sociedade brasileira, haja vista que deve prevalecer o superior interesse da criança e do adolescente, conforme previsto no sistema interno e internacional de proteção.

Palavras-chave: Trabalho infantil. Proteção. Exploração.

\section{Abstract}

Child Labor is a complex matter that excels the notion of child and adolescent defense, interfering in socioeconomic matters. This work aims to analyse the main factors that sustain Child Labor and its implications in the casting of the social structure in which the working child's family is inserted. Most times, the child's and family's survival is the main cause of child labor, since the subtraction of income earned by the child puts the family under the poverty line. In this perspective, programs against child 
labor demand a new approach, new strategies of structural reorganization in Brazilian society, so that the superior interest of the child and adolescent, will prevail as foreseen in the internal and international system.

Key words: Child labor. Protection. Exploration.

\section{INTRODUÇÃO}

0 trabalho infantil é tema que merece estudos mais detalhados. Apesar de bastante debatido, ainda desperta interesse para melhor compreensão de sua natureza. Sua configuração possibilita despertar uma profunda reflexão do significado do trabalho infantil numa sociedade em que produz novas formas de exploração.

Diversos enfoques podem ser atribuídos ao trabalho infantil, o que lhe empresta o caráter de questão complexa que ultrapassa as noções de defesa da criança e a garantia de seus direitos, imiscuindo-se nas questões econômico-sociais.

O trabalho sempre foi considerado um fator por excelência para a existência do ser humano, consistindo em atividade produtiva e fonte de conhecimento. Neste sentido, acompanhou e ainda promove todo o processo de evolução humana. Por meio dele são auferidos os meios indispensáveis para satisfação de suas necessidades. Nesse universo, todas as pessoas, sejam criança ou não, utilizam-se de sua força de trabalho, modificando o ambiente natural de forma útil à própria vida.

0 problema surge quando a força de trabalho inclina-se para o exagero e para a exploração. A grande dificuldade, contudo, revela-se na identificação do trabalho da criança que seja de exploração e o que não é, considerando-o tolerável e até mesmo necessário para a própria sobrevivência do grupo familiar.

O objetivo do presente trabalho é analisar os bastidores do trabalho infantil, identificando os principais fatores que o sustentam e as suas implicações na moldagem da estrutura do mercado e da sociedade civil na qual está inserida a criança. 


\section{O TRABALHO INFANTIL: CARACTERIZAÇÃO}

De acordo com o Estatuto da Criança e do Adolescente, Lei no 8.069, de 13 de julho de 1990, considera-se "criança" aquela pessoa que se encontra na faixa etária entre zero e menos de 12 (doze) anos de idade, incompletos, e "adolescente" na faixa dos doze aos dezoito anos incompletos (art. 2․ do ECA). 0 ECA foi alterado pela Lei n. 12.852/2013 que instituiu o Estatuto da Juventude para introdução da expressão "jovem”, assim considerada a pessoa entre 15 e 29 anos de idade (art. $1^{\circ}$, Lei $n$. 12852/2013, Estatuo da Juventude).

O sistema legislativo brasileiro estabeleceu esse marco divisório, e certo que de acordo com o desenvolvimento evolutivo da criança, sendo que a Convenção sobre os Direitos da Criança, estabelece em seu art. 1․ que "considera-se como criança todo ser humano com menos de 18 anos de idade, a não ser que, em conformidade com a lei aplicável à criança, a maioridade seja alcançada antes".

Na seara trabalhista, a Constituição brasileira de 1988, proíbe qualquer forma de trabalho para menores de 16 anos, exceto na condição de aprendiz ${ }^{1}$. Por seu lado, a Consolidação das Leis do Trabalho - CLT ${ }^{2}$ refere-se como "aprendiz" pessoa entre 14 e 24 anos de idade (Lei n. 5598/2005; art. 428 da CLT), sendo que a partir de 16 anos é considerado "empregado".

A Convenção 138 da Organização Internacional do Trabalho - OIT ${ }^{3}$, estabelece que cada Estado-membro especificará a idade mínima para admissão a emprego e o trabalho em seu território (art. 1ํㅡ), complementando que a idade mínima, porém, não será inferior à idade de conclusão da escolaridade compulsória, ou, em qualquer hipótese não inferior a 15

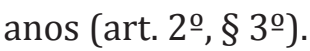

Apesar da proibição de trabalho a menores de 14 anos expresso na Constituição de 1988, pesquisa do Instituto Brasileiro de Geografia e Estatística - IBGE, mostra que mais de 870 mil pessoas entre cinco e 14 anos estavam ocupadas em 2012. ${ }^{4}$ Comparando com os dados de 2011, houve uma queda significativa, mais acentuada no grupo entre 10 e 13 anos, registrando, em termos percentuais, a 23\% de redução no ano de 
2012 (BRASIL - IBGE, PNAD, 2012). No entanto, no ano de 2012, somente esse segmento de menores, representou quase $5 \%$ da força de trabalho.

Um dado alarmante em termos de trabalho infantil diz respeito ao elevado número de crianças que moram e trabalham nas ruas, recolhendo reciclagens em lixões, ativam-se em bares, casas noturnas e que são levadas à exploração sexual e prostituição.

Esse patamar indica a existência do fenômeno conhecido como "trabalho infantil" e certo que proibido, de alto risco para essa camada populacional vulnerável e em peculiar condição de desenvolvimento e de formação.

De acordo com o Plano Nacional ${ }^{5}$ de Prevenção e Erradicação do Trabalho Infantil e Proteção ao Adolescente Trabalhador (BRASIL, 2011 p.6) entende-se por "trabalho infantil as atividades econômicas e/ou atividades de sobrevivência, com ou sem finalidade de lucro, remuneradas ou não, realizadas por crianças ou adolescentes em idade inferior a 16 (dezesseis) anos, ressalvada a condição de aprendiz a partir de 14 anos, independentemente de sua condição ocupacional".

Cotejando o texto das Convenções 138 e $182^{6}$ da Organização Internacional do Trabalho, é possível estabelecer as seguintes características do trabalho infantil:

a) Dos 5 aos 11 anos: todas as crianças envolvidas em atividades econômicas, exceto tarefas domésticas;

b) Dos 12 aos 14 anos: todas as crianças envolvidas em atividades econômicas, exceto as que têm trabalho leve, com cerca de 14 horas semanais e que não põe em risco a segurança, a saúde e o desenvolvimento moral;

c) Dos 15 aos 17 anos: todas as crianças que exercem as piores formas de trabalho infantil: escravatura, tráfico, trabalhos forçados, prostituição, conflito armado, atividades ilícitas e outras que, por sua natureza ou pelas circunstâncias, são suscetíveis de prejudicar a saúde, a segurança e a moral das crianças.

Mas, segundo Macedo (2011, p. 7), nem toda atividade da criança pode ser considerada trabalho infantil, afirmando que algumas vezes, a 
introdução da criança no trabalho pode ter dimensão de socialização e de aquisição de responsabilidades (SANTOS, 2010, p. 99).

Oliveira (2013, p. 19) acrescenta que, por haver diversas formas de trabalho de crianças, recentemente iniciou-se uma discussão doutrinária, propondo no cenário internacional diferenciação entre Child work e Child labor. Explica a autora que a primeira expressão designa um trabalho "tolerável", englobando, por exemplo, as atividades domésticas ao lado de membros adultos da família (OLIVEIRA, 2013, p. 20) nas quais seriam eliminados os riscos à segurança da criança, permitindo-lhe frequência à escola.

Já a expressão Child labor seria utilizada para designar os trabalhos considerados intoleráveis, seja pelo caráter perigoso, que colocam em risco a saúde, a segurança e a moral das crianças, seja pelo caráter exploratório com intensa carga horária e prejudicial à sua formação.

Na visão de Oliveira (2013, p. 21) as duas expressões quando traduzidas para a maior parte das línguas do mundo não fazem distinção, propondo a utilização de "emprego infantil" (child work) para designar atividades, como por exemplo, eventuais trabalhos efetivados fora das horas escolares ou durante as férias pelas crianças (MACEDO, 2011, p.7), nos limites fixados pela Organização Internacional do Trabalho. Ou seja, trabalho leve, que não ultrapasse 14 horas semanais para aqueles com idade entre 12 e 14 anos, ou que tenham idade entre 15 e 17 anos, mas que exercem atividades que não configurem nas piores formas de trabalho infantil. De outro lado, o "trabalho infantil" deveria ser utilizado como expressão traduzida de child labor.

Oliveira esclarece, porém, que o trabalho infantil deve ser entendido de acordo com o contexto em que as famílias vivem (2013, p. 23), devendo-se analisar também o arcabouço da estrutura social da comunidade, citando como exemplo Moçambique, na África, em que o trabalho, muitas vezes, confere às crianças uma forma concreta de aprendizagem de um conjunto de saberes necessários para obter recursos econômicos, através de estratégias familiares que envolvem respeito, cumplicidade e responsabilidade.

No Brasil, por "trabalho infantil" refere-se àquele realizado por pessoa abaixo da idade mínima fixada (16 anos, com exceção dos aprendizes, 
a partir dos 14), merecendo alguns comentários, já que inclui todos e quaisquer trabalhos, independente de remuneração, horas trabalhadas, ou se o objetivo é a sobrevivência ou a exploração.

\section{SISTEMA DE PROTEÇÃO ESPECIAL AOS DIREITOS FUNDA- MENTAIS DA CRIANÇA E DO ADOLESCENTE}

A criança e o adolescente como pessoas em peculiar condição de desenvolvimento físico, psíquico, moral, social e espiritual gozam de um sistema internacional e interno de proteção especial aos direitos humanos e fundamentais, cujos sistemas baseados nos princípios da proteção especial e do superior interesse visam o desenvolvimento sadio e com espírito de paz, compreensão, amor e solidariedade da criança e do adolescente.

Diversos documento internacionais anunciaram o sistema de proteção integral e especial aos direitos humanos infanto-juvenis da criança e do adolescente, dentre eles a Declaração de Genebra sobre os Direitos da Criança (1924), a Declaração Universal de Direitos Humanos (1948), a Declaração sobre os Direitos da Criança (1959); o Pacto de Direitos Civis e Políticos (1966), o Pacto dos Direitos Sociais, Econômicos e Culturais (1969), cujos documentos exaltaram a imaturidade física e psíquica da criança, razão pela qual necessitam de um sistema jurídico especial de proteção sob a responsabilidade da família, da sociedade e do Estado.

Contudo, o documento internacional que representou o ponto de partida para o reconhecimento da criança e do adolescente como sujeitos de direitos fundamentais especiais, e universalmente garantidos, é a Convenção Internacional dos Direitos da Criança (1989), que impõe o reconhecimento de direitos humanos e fundamentais especiais diante da peculiar condição dessas pessoas em desenvolvimento e também impõe aos Estados-partes o dever de prestação, com prioridade absoluta e de acordo com o melhor e superior interesse da criança.

O sistema internacional de proteção além de anunciar e tutelar direitos fundamentais relacionados à vida, saúde, educação, lazer, convivência familiar e comunitária, também abrange a proteção ao trabalho infantil 
e coíbe todo tipo e forma de violência que atente à dignidade humana dessa parcela vulnerável da população, rechaçando a exploração sexual e a exploração do trabalho da criança e do adolescente.

A Convenção Internacional sobre os Direitos da Criança garante a proteção especial contra todo tipo de violência, tratamento cruel, maus tratos, crueldade e exploração do trabalho infantil, e, nesse sentido, o artigo 19. da Convenção sobre os Direitos da Criança impõe que os Estados-partes adotem:

[...] medidas legislativas, administrativas, sociais e educativas adequadas à proteção da criança contra todas as formas de violência física ou mental, dano ou sevícia, abandono ou tratamento negligente; maus tratos ou exploração, incluindo a violência sexual, enquanto se encontrar sob a guarda de seus pais ou de um deles, dos representantes legais ou de qualquer outra pessoa a cuja guarda haja sido confiada.

Quanto à exploração e proibição do trabalho infantil, o art. 32 da Convenção sobre os Direitos da Criança dispõe:

1 - Os Estados Partes reconhecem o direito da criança de estar protegida contra a exploração econômica e contra o desempenho de qualquer trabalho que possa ser perigoso ou interferir em sua educação, ou que seja nocivo para sua saúde o para seu desenvolvimento físico, mental, espiritual, moral ou social.

2 - Os Estados Partes adotarão medidas legislativas, sociais e educacionais com vistas a assegurar a aplicação do presente Artigo. Com tal propósito, e levando em consideração as disposições pertinentes de outros instrumentos internacionais, os Estados Partes deverão, em particular: a) estabelecer uma idade mínima ou idades mínimas para a admissão em emprego;

b) estabelecer regulamentação apropriada relativa a horários e condições de emprego;

c) estabelecer penalidades ou outras sanções apropriadas a fim de assegurar o cumprimento efetivo do presente Artigo

A Convenção sobre os Direitos da Criança estabeleceu como viga mestra de todo sistema internacional de proteção os princípios da proteção e cuidado especial e do superior interesse, com intuito de tutelar integralmente os direitos fundamentais da criança e do adolescente, que 
se encontram "em situação especial de maior vulnerabilidade, ensejadora da outorga de um regime especial de salvaguarda, que lhes permitam construir suas potencialidades humanas em sua plenitude" (MACHADO, 2003, p. 108), buscando garantir o desenvolvimento e formação integrais, necessitando, dessa forma, de um ius singulare com relação ao ius commune (BOBBIO, 2004, p. 34).

Os direitos da criança e do adolescente diferem-se dos direitos fundamentais dos adultos, pois são mais amplos, conforme se depreende do ECA e do art. 227 da CF/88, portanto, em termos quantitativos; e também diferem em termos qualitativos, visto que integra o sistema de proteção especial com o dever de proteção a cargo da família, da sociedade e do Estado.

\section{TUTELA CONSTITUCIONAL E INFRACONSTITUCIONAL À FORÇA DE TRABALHO INFANTIL NO BRASIL}

Com fulcro no sistema internacional de proteção que está calcado nos princípios da proteção especial e do melhor interesse infanto-juvenil, o Brasil adotou, na defesa do direitos humanos e fundamentais da criança e do adolescente, a doutrina da Proteção Integral, conforme dispõe o artigo 227 da CF/88, cujo artigo versa sobre direitos humanos da população infanto-juvenil, consagrando, por outro lado, o sistema de dever de cumprimento integral, a cargo da família, da sociedade e do Estado.

0 artigo 227 foi regulamento pelo ECA que incorporou o melhor interesse sob a denominação da prioridade absoluta, declarando que a criança e o adolescente gozam de todos os direitos fundamentais inerentes à pessoa humana, com prioridade absoluta, ou seja, primazia ou preferência para as políticas sociais públicas e no atendimento de forma geral, como dever da família, da comunidade, da sociedade civil e do Poder Público (art. 227 da CF; artigos $3^{\circ}$ e 4odo ECA).

A CF/88 exaltou o valor social do trabalho, cuja ordem social tem como base o primado do trabalho (art. 193 da CF/88), constituindo-se também um dos fundamentos do Estado Democrático de Direito e da República Federativa do Brasil (art. 1ํ, IV, CF/88), cujo trabalho produtivo e em condições decentes é um direito fundamental e social que repre- 
senta extensão da dignidade da pessoa humana, sendo o trabalho meio de produção de riqueza, inserção social e valorização da pessoa humana.

Contudo, a entrega da força de trabalho físico ou intelectual depende do desenvolvimento físico e psíquico da pessoa humana, ou seja, requer maturidade física e psíquica, e, assim sendo, somente a partir de certa idade é que se deve dispor da força de trabalho, e, nesse sentido, no Brasil a capacidade laboral começa a partir dos 16 anos, salvo na condição de aprendiz a partir dos 14 anos, cujo contrato de aprendizagem está previsto no artigo 428 da CLT e configura um contrato de trabalho especial, posto que regido por condições especiais de trabalho, tal como prazo determinado e com a finalidade de oferecer formação técnico-profissional metódica, segundo as diretrizes e bases da educação nacional (arts. 62/64 do ECA; Lei n. 9394/96-Lei de Diretrizes e Bases da Educação-LDB).

$\mathrm{Na}$ esfera constitucional, conforme demonstrado alhures, o legislador constituinte estabeleceu a capacidade laboral e, consequentemente, a proibição do trabalho dos menores de 16 anos, salvo na condição de aprendiz (de 14 a 24 anos), cuja regra está em conformidade com o sistema internacional de proteção infanto-juvenil que impõe no âmbito interno um sistema de proteção que considere a imaturidade física, psíquica, pois, até os 16 anos a criança está na fase de formação física, moral, social, intelectual e educacional, necessitando de formação básica e obrigatória em matéria de educação.

Quanto às condições de trabalho do adolescente, a CF/88, em seu artigo 7ํㅡㄹ inciso XXXIII, proíbe o trabalho noturno, perigoso ou insalubre aos menores de 18 anos, e, no mesmo sentido, há vedação expressa nos art. 404 e 405 da CLT (Consolidação das Leis do Trabalho, Decreto-lei n. 5452/1943), ressaltando, também, o legislador infraconstitucional no artigo 405 que é vedado trabalho da criança e do adolescente em lugares ou serviços que atentem ao desenvolvimento físico, psíquico e moral do adolescente (art. 67 do ECA).

A Recomendação n. 190 da OIT caracteriza os trabalhos perigosos. Dessa forma, são consideradas como piores formas de trabalho infantil: a) sujeição à escravidão ou à condição análoga à de escravo, como é o caso do tráfico de crianças, servidão por dívidas, a condição de servo e o trabalho escravo ou compulsório; b) o recrutamento forçado ou obriga- 
tório de meninos para utilização em conflitos armados; c) o emprego de crianças na prostituição, a produção de pornografia ou ações pornográficas; d) a utilização, o recrutamento ou o oferecimento de crianças para a realização de atividades ilícitas, como a produção e tráfico de drogas; o trabalho que prejudique a saúde, a segurança e a moral das crianças.

Em contrapartida, o direito à profissionalização é um direito fundamental especial da criança e do adolescente, consagrado no art. 227 da CF/88 e regulamentado pelo ECA, cujo direito à profissionalização, nos termos do art. 69 do ECA, deve respeitar a condição peculiar de pessoa em desenvolvimento e a capacitação adequada ao mercado de trabalho, sobrepondo-se o aspecto pedagógico do trabalho sobre o aspecto produtivo.

0 direito à profissionalização visa proteger o interesse da criança $\mathrm{e}$ do adolescente no sentido de prepara-los adequadamente para o exercício do trabalho quando na idade adulta (MACHADO, 2005, p. 188), garantindo-se capacitação e igualdade para inserção no mercado de trabalho (MACHADO, 2005, p. 189), cuja profissionalização está atrelada à educação profissional regulada pela LDB (Lei n. 9394/96), dispondo o artigo 39 da LDB que "a educação profissional, integrada às diferentes formas de educação, ao trabalho, à ciência e à tecnologia, conduz ao permanente desenvolvimento de aptidões para a vida produtiva".

\section{TRABALHO INFANTIL: SOBREVIVÊNCIA OU EXPLORAÇÃO?}

O Brasil convive com o trabalho infantil desde os tempos mais remotos. Apesar de atualmente contar com leis restritivas, dados estatísticos mostram que o trabalho infantil ainda é uma realidade no Brasil. Muito embora, como adverte Kassouf (2007, p.328) as estatísticas ou são superestimadas ou subestimadas, pois muitas vezes, são incluídas crianças que trabalham até uma hora por semana, ou são excluídas aquelas que se ativam no trabalho doméstico.

Grande parte dos autores que estudam o problema do trabalho infantil no Brasil aponta a pobreza como determinante fundamental para a entrada precoce ao trabalho (KASSOUF, 2002, p. 89, 2007, p. 56; MARQUES, 2001, p. 119; MACEDO, 2011, p. 7; GIOSA, 2010, p. 48; MUNIZ, 2008, p. 66).

Macedo (2011, p. 7) argumenta que além da pobreza, a insuficiência 
das instituições escolares também é apontada como causa do trabalho infantil. Esclarece a autora que as causas do trabalho infantil devem ser analisadas sob os enfoques da oferta e da procura (MACEDO, 2011, p. 8). Nesse sentido, a pobreza, os costumes, as tradições locais e o número de componentes familiares são fatores que se relacionam com a oferta de mão de obra infantil; enquanto as exigências familiares, o sistema econômico e a aptidão específica das crianças são fatores relacionados com a procura.

Para Kassouf (2002, p. 5) o tamanho da família também determina a oferta de trabalho infantil, assim, quanto maior o número de irmãos mais jovens, maior é a probabilidade de a criança trabalhar. Embora o salário recebido pelas crianças seja menor, a família não corre o risco de sofrer solução de continuidade no ingresso dos rendimentos em caso de desemprego dos adultos, permitindo a sobrevivência da família.

De outro lado, a estrutura do mercado de trabalho que procura por mão de obra mais barata, contribui para a elevação dos índices de trabalho infantil. Entende Kassouf (2002, p. 6) que se os adultos fossem mais produtivos que as crianças e o salário pago mais compatível, o mercado preferiria contratar adultos e não crianças. Muniz (2008, p. 70) acrescenta ainda que o trabalho infantil agrava a crise do emprego dos adultos, que muitas vezes, ocupa vaga de trabalho dos adultos, além de perpetuar menor desenvolvimento econômico.

Embora não tenha estudos comprovando a relação entre o desenvolvimento econômico e mão de obra infantil (MUNIZ, 2008, p. 71), é possível inferir essa situação em face de existir maior produtividade entre adultos do que entre crianças. Estas, em razão da idade são imaturas e inexperientes, compondo grupos mais vulneráveis estando, portanto, sujeitos a maiores riscos de acidentes no trabalho; consequentemente haverá maior custo na manutenção dessa mão de obra.

$\mathrm{Na}$ análise de Kassouf (2002, p. 89), o trabalho infantil perpetua o ciclo de pobreza. Isto porque, quando se é pobre não tem aptidão para trabalhos mais especializados por falta de acesso escolar, o que leva a criança a se ativar em trabalhos sem perspectiva de crescimento e de melhora na fase adulta. A escolaridade prejudicada reflete nos rendimentos, perpetuando o ciclo de pobreza, uma vez que apenas legislações proibitivas 
do trabalho infantil não ajudam as crianças necessitadas, ao contrário, empurram-nas cada vez mais para o trabalho informal mantendo o ciclo.

Por este ponto de vista, o trabalho infantil é sinônimo de sobrevivência da família, já que as necessidades mínimas não são atendidas. Alguns estudos têm evidenciado que o trabalho infantil é encarado como uma forma alternativa de complementação de renda familiar para fugir da pobreza, passando a ser então uma estratégia de sobrevivência (MUNIZ, 2008, p. 66). Pesquisa realizada por Alberto et al. (2010, p. 64) confirma que o principal motivo do trabalho infantil foi "necessidade financeira", referenciado por $63,3 \%$ das famílias.

$\mathrm{Na}$ análise de Marques (2001, p. 119), a maioria das crianças que trabalham não tinha pai presente ou este estava desempregado. Nessa situação, a falta de um provedor da família, faz com que as crianças sejam colocadas na posição de mantenedores do grupo familiar. Há, assim, um deslocamento dos papéis familiares, para que o grupo seja mantido (MARQUES, 2001, p. 120).

A pobreza e exclusão social são fatores que impulsionam a exploração da mão de obra infantil, seja por parte da família, seja por parte do sistema capitalista fruto do neoliberalismo econômico exsurgido da globalização econômica. Contudo, a eliminação da pobreza e da exclusão econômica e social não se atinge com a exploração do trabalho infantil, mas permitindo o acesso à educação e à profissionalização, sem retirar o direito da criança de brincar e de lazer, inclusive ao ócio, posto que esses fatores corroboram para a sua formação integral.

Oliveira e Robazzi (2001, p. 87) argumentam que além da pobreza, também o sistema de produção e a estrutura do mercado de trabalho são fatores impulsionadores do trabalho infantil. É comum, segundo esses autores, a situação em que o trabalho dos adultos de uma família, em razão dos baixos salários, não é suficiente para a sobrevivência do grupo, forçando outros membros a contribuir no suprimento das necessidades.

Situação semelhante foi constatada por Sartori (2006, p. 261), na pesquisa realizada em Franca - polo de fabricação de calçados no Estado de São Paulo. Nessa região há uma disseminação do trabalho infantil, principalmente entre famílias sem recursos financeiros, desassistidas e sem atendimento pelas políticas públicas sociais, as quais veem a in- 
clusão das crianças no mercado de trabalho como única alternativa de sobrevivência.

Muitas vezes, parte do trabalho industrial na confecção de calçado é transferida para realização na própria residência, onde todos os membros da família auxiliam na execução da tarefa, chegando a se ativar por até dez horas diárias (SARTORI, 2006, p. 276). Por ser trabalho executado no interior da residência é difícil a fiscalização do trabalho infantil, porém os pais o defendem, pois acreditam que, ainda que seja desumano e mal remunerado, o trabalho permitirá à criança a aprendizagem de um ofício e a disciplina, ambas necessárias no futuro (SARTORI, 2006, p. 277).

Efetivamente a fiscalização contra o trabalho infantil não é tarefa fácil, principalmente quando se ativa no interior do domicílio. É o que afirma Custódio (2006, p. 92), particularmente porque é um trabalho que está desvinculado do sistema econômico. Para este autor, o trabalho infantil doméstico decorre não apenas do empobrecimento da população, mas principalmente da continuidade da dinâmica histórica (CUSTÓDIO, 2006, p. 93). Dreissig et al. (2005, p. 97) destacam que, muitas vezes, a execução do trabalho doméstico tem como referência o estabelecimento de laços afetivos, de manter a coesão do grupo, sendo a força do trabalho que caracteriza essa integração. Nessa dinâmica, o ambiente doméstico constitui o espaço para o compartilhamento de tarefas; faz parte da socialização da criança com o desenvolvimento do trabalho coletivo, solidário e de convivência (CUSTÓDIO, 2006, p. 100).

Nesse aspecto, pesquisas realizadas por Cardoso e Souza (2011, p. 169), numa comunidade ribeirinha do Amazonas constataram que a vida cotidiana das crianças daquela localidade se traduz na participação, não só do trabalho, mas também dos cultos religiosos, do lazer e das conversas. Os membros da comunidade têm a percepção de que a vida infantil tem por objetivo a formação do indivíduo e o ideal do que é ser adulto. Desse modo, o trabalho infantil não é encarado como se a criança fosse igual ou substituto dos pais, mas que é imprescindível para a socialização, pois encadeia um conjunto de significados simbólicos (CARDOSO e SILVA, 2011, p. 170).

Para esses autores a incorporação do trabalho na fase infantil cria disposições duráveis no modo de vida, na forma de pescar, de manejar a terra, de cuidar do gado, atividades peculiares às comunidades tradicio- 
nais da Amazônia (CARDOSO e SILVA, 2011, p. 170). Na análise desses autores, o trabalho da criança determina o habitus histórico, já que é emprestado o sentido de processo de socialização, com a internalização da estrutura social vigente, além de permitir criatividade, principalmente nas habilidades com os instrumentos (CARDOSO e SILVA, 2011, p. 172).

Nessas comunidades, concluem Cardoso e Silva (2011, p. 176), a inserção das crianças desde cedo nas atividades de trabalho, junto com os adultos, visa prepara-las para se tornarem adultas, independentes, capazes de construir sua própria família, com os saberes básicos que lhe foram administrados. Desse modo, não há como conceber, nessa situação, o trabalho como forma de exploração da criança.

Semelhante resultado foi observado por Oliveira (2013, p. 23) em algumas comunidades da África, contexto na qual o trabalho das crianças faz parte do processo de socialização e não é considerado perigoso ou exploratório. A análise do trabalho das crianças, esclarece a autora, deve ser estudada no contexto em que as família vivem.

A economia na África é permeada pela informalidade seja na própria estrutura, seja em relação ao mercado de trabalho. Os comportamentos econômicos são socialmente admissíveis e realizados com finalidade de sobrevivência: os trabalhadores, de maneira geral não têm qualquer vínculo laboral, os rendimentos não são contabilizados e a economia gira em torno de pequenas empresas ou atividades domésticas (OLIVEIRA, 2013, p. 27).

Pesquisa realizada em Moçambique revelou que as crianças são fundamentais para a estratégia familiar, pois ajudam nas tarefas domésticas e nos negócios da família. Ao participar das atividades, as crianças compreendem o significado das práticas, das normas e valores a elas inerentes, desenvolvem confiança e autoestima e são valorizadas pela família ao adquirir conhecimento, competências e habilidades que vão ser úteis no futuro (OLIVEIRA, 2013, p. 77).

Essas referências são importantes na medida em que o trabalho, conforme salienta Erivan Santos (2010, p. 99), tem a potencialidade de ser um ato criador de riquezas a serviço da coletividade, todavia a incorporação das crianças nesse mercado pode assumir o caráter exploratório. A fim de que o trabalho atinja o seu objetivo, esse autor sugere que o 
trabalho da criança não deve ser sempre traduzido como trabalho infantil merecedor de reprimendas. Há que se analisar também as dimensões de socialização, da aquisição de responsabilidade e da produção, adequadas às possibilidades da criança.

O trabalho possui diversas dimensões: permite posicionar-se diante da realidade, conhecendo o modo de pensar, as crenças, os valores ético-culturais da comunidade; produz, pelas ações, o acúmulo de conhecimento e o domínio da técnica despertando a criatividade; aumenta o círculo de relacionamento e a satisfação de suas necessidades (SANTOS, 2010, p. 100).

Em termos de trabalho da criança, não se pode esquecer também o aspecto lúdico. As crianças de Moçambique analisadas por Oliveira (2013, p. 78) mesclavam trabalho com brincadeira, tornando a tarefa menos cansativa e mais prazerosa, tanto que, no entendimento das próprias crianças, o trabalho é "natural" e tem a função de afirmação social.

Importante ponderar que o trabalho infantil ou trabalho precoce compromete outro direito fundamental essencial da criança, qual seja, o direito à saúde, não apenas em razão de condições insalubres e de risco de acidentes a que estão mais propensas e certo que em razão da sua vulnerabilidade, como também pelo fato de que são pessoas em formação física e psíquica e em desenvolvimento cognitivo, tratando-se de grave violação a direito fundamental da criança e do adolescente e submissão dessa camada vulnerável ao trabalho, não atentando à proteção especial e integral, tão menos ao superior interesse da criança.

\section{A DIFÍCIL CONCILIAÇÃO ENTRE O TRABALHO INFANTIL E A SOBREVIVÊNCIA}

Os aspectos heterogêneos implicados na questão do trabalho infantil constituem grandes dificuldades no estabelecimento de medidas de combate à exploração. De um lado, os aspectos culturais e tradições familiares consideram o trabalho da criança como um "rito de passagem" ou um "processo de adulteza" (OLIVEIRA ROBAZZI, 2001, p. 86) pela aquisição de conhecimentos e preparação para a vida adulta; de outro, o aspecto econômico, que inclui a situação de pobreza, onde a renda auferida pelo 
trabalho das crianças constitui o sustento familiar; sem esquecer os aspectos sociais, como o baixo nível educacional e a dificuldade de acesso aos serviços oferecidos pela rede pública. Embora todos esses aspectos estejam interligados, o tratamento para superação do trabalho infantil em cada um deles deve ser distinto (KASSOUF, 2007, p. 345).

É claro que não se pode aceitar a exploração infantil em qualquer forma de manifestação, mas, no que concerne ao trabalho infantil no Brasil, não se pode rotular a família como o algoz de uma situação, em que sua origem se encontra na organização da própria sociedade brasileira (GIOSA, 2010, p. 72). Mesmo porque, como afirmam Oliveira e Robazzi (2001, p. 86), não é a família que inventa o trabalho infantil; existe na verdade, uma demanda de mercado para este trabalho e a família apenas utiliza esses meios para resolver o problema da sobrevivência.

Desse modo ainda que o trabalho infantil seja considerado estratégico para a sobrevivência da família e, portanto, passível de solução, também é condição de inserção social para famílias excluídas das oportunidades sociais (OLIVEIRA; ROBAZZI, 2001, p. 88).

Muniz (2008, p. 73) argumenta que o salário auferido pelo trabalho da criança é importante na renda familiar total, de tal modo que a exclusão desse rendimento significa crescimento do número de crianças em situação de extrema pobreza e indigência. Situação semelhante foi obtida pelos estudos de Kassouf (2007, p. 344) apontando que a proibição do trabalho infantil reduz o bem-estar das famílias que têm filhos trabalhando.

Esses estudos demonstram que se a renda da criança for subtraída, tende a ampliar a pobreza severa, configurando situação de família abaixo da linha de pobreza. Além disso, argumenta a autora, como a fiscalização contra o trabalho infantil só pode agir legitimamente no setor formal da economia, a proibição do trabalho de crianças só piora a situação das famílias, pois forçam-nas a trabalharem no setor informal.

No entendimento de Custódio (2006, p. 210), nem mesmo o programa de combate ao trabalho infantil proposto pelo governo não é eficaz, pois traz a marca da tradição da política pública brasileira, de uma cultura de caridade, de filantropia e assistencialismo. Analise da aplicação desse programa em São Paulo feita por Giosa (2006, p. 72) demonstra 
que os serviços assistenciais não são eficazes e não conseguem satisfazer as necessidades e anseios familiares. Uma das razões desse fracasso é referente a bolsa-auxílio: em São Paulo, a bolsa-auxílio oferecida pelo programa é de $\mathrm{R} \$ 122,00$, enquanto uma criança trabalhando três vezes por semana consegue uma renda média mensal de $\mathrm{R} \$ 360,00$.

Assim, para o combate ao trabalho infantil, políticas públicas mais eficazes se fazem necessárias, propondo mecanismos que não se limitem a substituir a renda gerada pelo trabalho das crianças, mas, também, políticas que fortaleçam a família, apresentem meios concretos de criar empregos dignos para a população, oferecer instrução e qualificação aos pais para melhorar sua remuneração.

Nas palavras de Custódio (2006, p. 211), será preciso uma reorganização de todas as instituições, de todos os serviços oferecidos, inclusive do fortalecimento do arcabouço jurídico ao lado das políticas públicas. Acrescente-se também a educação que precisa ser revista. Embora a educação não crie empregos produtivos, nem reduza a abundância de mão de obra infantil, nem amenize os males causados pela pobreza, ainda é o componente principal para o processo de desenvolvimento.

A educação, sem dúvida, é um meio de empoderamento da criança e do adolescente, desperta a consciência cidadã e a prepara para o protagonismo no seio da sociedade, em especial, na defesa de seus direitos e dos interesses da coletividade, no despertar para a consciência ambiental, social e de responsabilidade social, que leva à construção de uma sociedade justa, fraterna e solidária.

\section{CONCLUSÃO}

O trabalho infantil é multidimensional, abrange questões sociais, econômicas e culturais, o que exige tratamento distinto para cada um dos fatores componentes. Por outro lado, não obstante todo o arcabouço legislativo interno e as normas internacionais ditadas pela OIT, além das políticas públicas a cargo, principalmente, do Ministério do Trabalho, a exploração do trabalho infantil é uma realidade onipresente em todo o Brasil.

0 direito de ser criança, de brincar e não trabalhar e de viver a in- 
fância é um direito natural nessa fase de amadurecimento da vida, cujo direito não pode ser extirpado da criança, sob pena de violação a direito humano e fundamental, além de mazelas para a vida da criança explorada.

De acordo com as diretrizes traçadas pelo ECA e pela LDB, o adolescente deve ser conduzido para a educação profissional que o habilita e o insere no mercado de trabalho, além de servir de preparação para a vida adulta e obtenção de meios de sustento e de empoderamento pessoal, social e profissional através da qualificação profissional e inserção no mundo do trabalho e na vida social e familiar, cuja mão-de-obra não pode ser explorada com o fito de lucro, sob pena de flagrante violação aos direitos fundamentais especiais dessa parcela da população em formação moral, social, intelectual, social e espiritual.

No Brasil, a pobreza é um dos principais fatores indicados pelas pesquisas como causa preponderante do trabalho infantil. A proibição de trabalho infantil, sem um caminho alternativo para melhorar as condições de vida das famílias brasileiras, contribui para piorar a situação, levando muitas delas a se situarem abaixo da linha de pobreza.

Deve-se atentar para o detalhe de que o trabalho infantil é uma das causas da evasão escolar, o que justifica a reforma das diretrizes da educação básica para o fim de implantação da escola em tempo integral.

Para o combate ao trabalho infantil não basta apenas o repasse financeiro para substituir a remuneração do trabalho das crianças, por meio de programas sociais, tal como bolsa família etc; é preciso propor inicialmente uma remodelação da base de sustentação, ou seja, mudanças estruturais da economia, novos enfoques das instituições públicas e privadas, uma ampla reorganização da própria sociedade brasileira.

Além disso, ao lado das determinações legislativas e da própria Convenção sobre os Direitos da Criança que impõem medidas, ações e iniciativas a cargo dos Poderes Legislativo, Executivo e Judiciário, além das ações e medidas a cargo da sociedade e da família, com vistas à efetivação do proteção integral e do melhor interesse, há a necessidade de conscientização individual e social sobre os limites do trabalho infantil e das mazelas da sua exploração que conduz à violação a direitos humanos infanto-juvenis. 


\section{NOTAS}

1 CF/88. Art. 7ํ, XXXIII - Trabalho noturno e perigoso à saúde é proibido para crianças menores de 18 anos, enquanto qualquer forma de trabalho, é proibido a menores de 16 anos, salvo na condição de aprendiz, a partir de 14 anos (Redação dada pela Emenda Constitucional 20/1998).

2 CLT. art. 403. É proibido qualquer trabalho a menores de dezesseis anos de idade, salvo na condição de aprendiz, a partir dos quatorze anos (Redação dada pela Lei no 10.097, de 19.12.2000).

3 A Convenção 138 da OIT é conhecida como Convenção sobre Idade Mínima. Disponível em: < www.oit.org.br>. Acesso em: 21 jun. 2014.

4 IBGE - PNAD 2012 - Instituto Brasileiro de Geografia e Estatística, Pesquisa Nacional por Amostra de Domicílio 2012. Disponível em: <www.ibge.gov.br>. Acesso em: 21 junho 2014.

5 0 Ato n. 63/CSJT, de 14 de março de 2016, alterou a denominação do Programa de Combate ao Trabalho Infantil no âmbito da Justiça do Trabalho, instituído pelo Ato no 419/CSJT, de 11 de novembro de 2013, passando a ser denominado "Programa de Combate ao Trabalho Infantil e de Estímulo à Aprendizagem".

6 Convenção 182, da OIT, sobre Proibição das Piores Formas de Trabalho Infantil e Ação Imediata para sua Eliminação. Disponível em: <www.oit.gov.br>. Acesso em: 21 junho 2014.

\section{REFERÊNCIAS}

ALBERTO, Maria de Fátima Pereira; SILVA, Ana Cristina Serafim da; SOUZA, Gabriel Pereira de; NUNES, Taiana da Silva. 0 trabalho infantil na rua. Cadernos de Psicologia Social do Trabalho, v. 13, n. 1, p. 59-71, 2010. Disponível em www. scielo.br. Acesso em: 19 jun. 2014.

BOBBIO, Norberto. A era dos direitos. Tradução de Carlos Nelson Coutinho. Rio de Janeiro: Elsevier, 2004.

BRASIL. Plano Nacional de Prevenção e erradicação do trabalho infantil e proteção do adolescente trabalhador. Comissão Nacional de Erradicação do Trabalho Infantil. 2. ed. Brasília: Ministério do Trabalho e Emprego, 2011. 95 p.

BRASIL. IBGE - Instituto Brasileiro de Geografia e Estatística. Pesquisa Nacional por Amostra de Domicílio - PNAD, comentário, 2012. Disponível em: <www. ibge.gov.br>. Acesso em: 21 jun. 2014.

CARDOSO, Luís Fernando Cardoso e; SOUZA, Jaime Luiz Cunha. Viver, aprender e trabalhar: habitus e socialização de crianças em uma comunidade de pescadores da Amazônia. Boletim do Museu Paraense Emílio Goeldi. Ciências Humanas, Belém, v. 6, n. 1, p. 165-177, jan./abr. 2011. Disponível em: <www.scielo.br>. Acesso em: 19 jun. 2014. 
CUSTÓDIO, André Viana. A exploração do trabalho infantil doméstico no Brasil contemporâneo: limites e perspectivas para sua erradicação. Tese de Doutoramento em Direito, Universidade Federal de Santa Catarina, Florianópolis, 2006. Disponível em: <www.ufsc.br>. Acesso em: 19 jun. 2014.

DREISSIG, Juliana et al. 0 significado do trabalho infantil para os usuários da Assistência Social. Revista Opinio, Canoas, n. 14, p. 91-101, jan./jun. 2005. Disponível em: <www.ulbra.br>. Acesso em: 21 jun. 2014.

GIOSA, Beatriz Aparecida Nogueira. Trabalho infantil: entre a exploração e a sobrevivência. Dissertação de mestrado em Serviço Social, Pontifícia Universidade Católica de São Paulo, 2010. Disponível em: <www.sapientia.pucsp.br>. Acesso em: 16 jun. 2014.

KASSOUF, Ana Lúcia. O que conhecemos sobre o trabalho infantil. Revista Economia, Belo Horizonte, v. 17, n. 2, p. 323-350, ago. 2007. Disponível em: <www. scielo.br>. Acesso em: 21 jun. 2014.

Aspectos socioeconômicos do trabalho infantil no Brasil. Tese de Livre docência para Universidade de São Paulo, 2002. Disponível em: <www.cepea. esalq.usp.br>. Acesso em: 21 jun. 2014.

LAFER, Celso. A reconstrução dos direitos humanos: um diálogo com o pensamento de Hannah Arendt. São Paulo: Companhia das Letras, 1988.

MACEDO, Joana de Negier Almeida. Trabalho infantil: representações sociais nos media. Dissertação de Mestrado em Sociologia das Organizações e do Trabalho. Instituto Superior de Ciências Sociais e Políticas, Universidade Técnica de Lisboa, 2011. Disponível em: <www.repository.utl.pt>. Acesso em: 21 jun. 2014.

MACHADO, Martha de Toledo. A proteção constitucional de crianças e adolescentes e os direitos humanos. Barueri: Manole, 2005.

MARQUES, Walter Ernesto U. de. Trabalho infantil e contexto sociofamiliar: considerações acerca dos resultados de um estudo relativo às infâncias (pre) ocupadas. Revista Trabalho \& Educação, Belo Horizonte, n. 8, p.112-131, jan./ jun. 2001. Disponível em: <www.fae.ufmg.br>. Acesso em: 16 jun. 2014.

MARTINS, Sérgio Pinto. Direitos fundamentais trabalhistas. São Paulo: Atlas, 2008. 
MUNIZ, André Luiz Pires. 0 trabalho infantil: vale a pena? Um levantamento dos argumentos a favor e contra o trabalho infantil. Revista Educação Popular, Uberlândia, v. 7, p. 64-79, jan./dez. 2008. Disponível em: <www.ufu.br>. Acesso em: 21 jun. 2014.

OLIVEIRA, Deborah Capela de. Trabalho infantil e estratégias familiares: crianças nos mercados informais de Maputo. Dissertação de Mestrado em Estudos Africanos. Instituto Universitário de Lisboa, junho, 2013. Disponível em: <www. repositorio.iscte.iul.pt>. Acesso em: 21 jun. 2014.

OLIVEIRA, Beatriz Rosana Gonçalves; ROBAZZI, Maria Lúcia do Carmo Cruz. 0 trabalho na vida dos adolescentes: alguns fatores determinantes para o trabalho precoce. Revista Latino-americana de Enfermagem, Ribeirão Preto, v. 9. n. 3, p, 83-89, maio 2001. Disponível em: <www.scielo.br>. Acesso em: 19 jun. 2014.

PEREIRA, Tânia da Silva. Direito da criança e do adolescente: uma proposta interdisciplinar. 2. ed. Rio de Janeiro: Renovar, 2008.

PEREIRA, Tânia da Silva (Coord.). 0 melhor interesse da criança: um debate interdisciplinar. Rio de Janeiro: Renovar, 1999.

PIOVESAN, Flávia. Direitos humanos e o direito constitucional internacional. 8. ed. São Paulo: Saraiva, 2007.

. Temas de direitos humanos. 4. ed. São Paulo: Saraiva, 2010.

SARLET, Ingo Wolfgand. Dignidade da pessoa humana e direitos fundamentais na Constituição Federal de 1988. 3. ed. Porto Alegre: Livraria do Advogado, 2011.

SANTOS, Erivan Hilário dos. 0 trabalho como processo educativo/formativo. Revista de Educação do Vale do São Francisco, Petrolina, v.1, n. 1, p. 96-102, jun. 2010. Disponível em: <www.periodicos.univasf.edu.br>. Acesso em: 19 jun. 2014.

SARTORI, Elisiane. Trabalho infantil em Franca: um laboratório das lutas sociais em defesa da criança e do adolescente. Cadernos Pagu, Campinas, n. 26, p. $263-$ 278, jan./jun. 2006. Disponível em: <www.scielo.br>. Acesso em: 19 jun. 2014.

Recebido em: 7-6-2017

Aprovado em: 24-1-2018 


\section{Ana Maria Viola de Sousa}

Pós-doutora em Democracia e Direitos Humanos pela Universidade de Coimbra-Portugal/IUS Gentium Conimbrigae; doutora e Mestre em Direito das Relações Sociais (Direito Civil) pela Pontifícia Universidade Católica de São Paulo; professora e pesquisadora no Curso de Direito na Universidade do Vale do Paraíba (UNIVAP-São José dos Campos/SP); professora e pesquisadora nos cursos de Mestrado em Direito, Graduação e Pós Graduação no Centro Universitário Salesiano, UNISAL -U.E.Lorena/SP; professora e pesquisadora na Universidade Paulista (UNIP-São José dos Campos-SP); advogada. E-mail: amdvs@uol.com.br

Centro Universitário Salesiano, UNISAL. Unidade Lorena. R. Dom Bôsco, 284 Centro, Lorena - SP, 12600-100

\section{Maria Aparecida Alkimim}

Pós-Doutora em Democracia e Direitos Humanos pela Universidade de Coimbra/Ius Gentium Conimbrigae; doutora em Direito pela Pontifícia Universidade Católica de São Paulo (PUC-SP); mestre em Direito pela PUC-SP; coordenadora e pesquisadora do Programa de Mestrado em Direito do Centro Universitário Salesiano de São Paulo (UNISAL); professora integrante do Observatório de Violências nas Escolas, que compõe a Cátedra da UNESCO de Juventude, Educação e Sociedade. E-mail: maalkimin@terra.com.br

Centro Universitário Salesiano, UNISAL. Unidade Lorena. R. Dom Bôsco, 284 Centro, Lorena - SP, 12600-100 